Short paper

\title{
Women have worse cognitive, functional, and psychiatric outcomes at hospital discharge after cardiac arrest
}

\author{
Sachin Agarwal ${ }^{a, *}$, Alex Presciutti ${ }^{\mathrm{a}}$, Jayati Verma ${ }^{\mathrm{a}}$, Marykay A. Pavol ${ }^{\mathrm{a}}$, Deepti Anbarasan ${ }^{\mathrm{a}}$, \\ Daniel Brodie ${ }^{\mathrm{b}}$, Leroy E. Rabbani ${ }^{\mathrm{b}}$, David J. Roh ${ }^{\mathrm{a}}$, Soojin Park ${ }^{\mathrm{a}}$, Jan Claassen ${ }^{\mathrm{a}}$, Yaakov Stern ${ }^{\mathrm{a}}$ \\ a Department of Neurology, Columbia University College of Physicians \& Surgeons, New York Presbyterian Hospital/Columbia, New York, NY 10032, United States \\ ${ }^{\mathrm{b}}$ Department of Internal Medicine, Columbia University College of Physicians \& Surgeons, New York Presbyterian Hospital/Columbia, New York, NY 10032, United States
}

\section{A R T I C L E I N F O}

\section{Keywords:}

Gender disparity

Cardiac arrest

Cognition

Psychiatric disorder

Disability

Functional outcomes

\begin{abstract}
A B S T R A C T
Aim: To examine gender differences among cardiac arrest (CA) survivors' cognitive, functional, and psychiatric outcomes at discharge.

Methods: This is a prospective, observational cohort of 187 CA patients admitted to Columbia University Medical Center, considered for Targeted Temperature Management (TTM), and survived to hospital discharge between September 2015 and July 2017. Patients with sufficient mental status at hospital discharge to engage in the Repeatable Battery for Neuropsychological Status (RBANS), Modified Lawton Physical Self-Maintenance Scale (M-PSMS), Cerebral Performance Category Scale (CPC), Center for Epidemiological Studies Depression Scale (CES-D), and Post-Traumatic Stress Disorder Checklist - Civilian Version (PCL-C) were included. Fisher's exact, Wilcoxon Rank Sum, and regression analysis were utilized.

Results: 80 patients (38\% women, 44\% white, mean age $53 \pm 17$ years) were included. No significant gender differences were found for age, race, Charlson Comorbidity Index, premorbid CPC or psychiatric diagnoses, arrest related variables, discharge CPC, or PCL-C scores. Women had significantly worse RBANS (64.9 vs 74.8, $\mathrm{p}=.01)$, M-PSMS (13.6 vs 10.6, $\mathrm{p}=.02)$, and CES-D (22.8 vs $14.3, \mathrm{p}=.02)$ scores. These significant differences were maintained in multivariate models after adjusting for age, initial rhythm, time to return of spontaneous circulation, and TTM.

Conclusions: Women have worse cognitive, functional, and psychiatric outcomes at hospital discharge after cardiac arrest than men. Identifying factors contributing to these differences is of great importance in cardiac arrest outcomes research.
\end{abstract}

\section{Introduction}

Gender differences in cardiac arrest (CA) exist; women are typically older, present with a higher rate of non-shockable rhythms, receive fewer therapeutic treatments over the course of their care, and experience higher in-hospital mortality when compared to men $[1,2]$. Moreover, post-stroke, women have been shown to have worse cognitive [3], functional [4], and psychiatric [5] outcomes at discharge even after adjusting for baseline differences in demographics and clinical variables. There is a paucity of data looking at these detailed outcomes after CA, which has been limited to crude scales such as the Cerebral Performance Category Scale (CPC) [2,6]. Thus, the current study aims to examine gender differences at hospital discharge after CA using indepth cognitive, functional, and psychiatric outcomes.

\section{Methods}

\section{Patient characteristics}

This study is a subgroup analysis of an observational, prospective, cohort study evaluating the long-term evolution of cognitive, functional, and psychiatric manifestations of CA survivors. Patients were $\geq 18$ years of age, resuscitated following either in-hospital or out-ofhospital CA, admitted to Columbia University Medical Center, considered for Targeted Temperature Management (TTM), and survived to hospital discharge between September 2015 and July 2017.

\section{Screening procedure}

Through daily ICU screening, potential subjects were identified

\footnotetext{
* Corresponding author at: Department of Neurology, Columbia University College of Physicians \& Surgeons, New York Presbyterian Hospital/Columbia, 177 Ft Washington Ave, MHB8-300 Center, New York, NY 10032, United States.

E-mail address: sa2512@columbia.edu (S. Agarwal).
} 
using diagnostic codes and approached for written informed consent. Survivors with sufficient mental status to engage in an in-person neuropsychological exam and an evaluation for functional and psychiatric status at discharge were eligible. Sufficient mental status was defined as having a Cerebral Performance Category Scale (CPC) [7] of 3 or less, being alert and oriented to person, place, and date, and having no presence of delirium, agitation, or sedation according to the Confusion Assessment Method for the ICU [8] and the Richmond Agitation-Sedation Scale [9]. 191 of 358 admitted patients survived to hospital discharge; 85 (41 women) did not meet criteria for sufficient mental status. 106 patients were deemed eligible, of which 26 (11 women) declined to participate due to travel limitations for follow-up appointments as part of the parent study, and were therefore not included in the present analysis. 80 patients gave consent and were included in the final analysis. The study was approved by Columbia University's institutional review board.

\section{Data collection}

Following Utstein guidelines [10], demographic information (i.e. age, gender, race), pre-arrest variables (i.e. obesity, Charlson Comorbidity Index (CCI), CPC, psychiatric diagnoses), and arrest-related variables (i.e. arrest site, witnessed arrest, bystander cardiopulmonary resuscitation (CPR), initial rhythm, defibrillation, time to return of spontaneous circulation (ROSC), TTM administration) were collected. Cooling protocol has been published previously [11]. Details on TTM exclusion are attached in a supplementary file 1 . Level of care provided was measured by the Simplified Therapeutic Intervention Scoring System (TISS-28) [12,13].

\section{Outcome measures}

Outcome measures were administered at hospital discharge (median 22 days from arrest date).

Cognitive status was measured through the Repeatable Battery for the Assessment of Neuropsychological Status (RBANS). The RBANS assesses immediate memory, semantic fluency, attention, visuospatial awareness, and delayed memory [14]. RBANS administration was performed by a single reviewer (AP) who was trained by a board certified neuropsychologist (MP). Results were scored according to the publisher's normative data.

Level of independence was calculated via the Lawton Physical Self Maintenance Severity Scale (M-PSMS) [15]. Functional status was measured via the CPC using a rubric (attached as supplemental file 2) [11]. Scores were adjudicated through physical and occupational therapy notes.

Psychiatric symptomatology was assessed via the Center for Epidemiological Studies Depression Scale (CES-D) [16] and the PostTraumatic Stress Disorder (PTSD) Checklist - Civilian Version (PCL-C) [17], which are commonly used as interview-based diagnostic screeners for depression (CES-D score $\geq 16$ ) [16] and PTSD (PCL-C score $\geq 36$ ) [18], respectively.

\section{Statistical analyses}

Fisher's exact and Wilcoxon-Rank Sum tests were used to compare differences between genders in demographics, pre-arrest and arrestrelated variables (Table 1 ), and recovery outcome measures (Table 2). Multivariate regression models were then created to explore associations between gender and outcome measures. Selection of variables included in the final models was based on either a statistical significance of $\mathrm{p}<.05$ or clinical importance based on prior studies. CPC greater than 2 was defined as severe cerebral disability.
Table 1

Admission Clinical Characteristics Comparing Women and Men.

\begin{tabular}{|c|c|c|c|}
\hline $\begin{array}{l}\text { Admission Clinical } \\
\text { Characteristics }\end{array}$ & $\begin{array}{l}\text { Women } 37.5 \% \\
(\mathrm{n}=30)\end{array}$ & $\begin{array}{l}\text { Men } 62.5 \% \\
(n=50)\end{array}$ & $\mathrm{p}$-value \\
\hline \multicolumn{4}{|l|}{ Demographics } \\
\hline Age, mean $\pm S D$ & $50.1 \pm 17.0$ & $54.6 \pm 17.0$ & .24 \\
\hline Race, $\%(\mathrm{n})$ & & & .74 \\
\hline -White & $40.0(12)$ & $46.0(23)$ & \\
\hline -Black & $23.3(7)$ & $26.0(13)$ & \\
\hline -Hispanic & $26.7(8)$ & $16.0(8)$ & \\
\hline -Asian & $10.0(3)$ & $12.0(6)$ & \\
\hline \multicolumn{4}{|l|}{ Premorbid Information } \\
\hline $\begin{array}{l}\left.\text { Obesity (BMI }>30 \mathrm{~m} / \mathrm{kg}^{2}\right), \% \\
\text { (n) }\end{array}$ & $14.8(4)$ & $18.0(9)$ & 1.00 \\
\hline CCI, median (IQR) & $3(0.5-4)$ & $2(1-4)$ & .84 \\
\hline Premorbid CPC, \% (n) & & & 0.78 \\
\hline -CPC 1 & $96.6(28)$ & $94.0(47)$ & \\
\hline- CPC 2 & $0.0(0)$ & $4.0(2)$ & \\
\hline -СРC 3 & $3.5(1)$ & $2.0(1)$ & \\
\hline $\begin{array}{c}\text { Premorbid Psychiatric } \\
\text { Diagnoses, \% (n) }\end{array}$ & $6.7(2)$ & $10.0(5)$ & .71 \\
\hline \multicolumn{4}{|l|}{ CA Variables } \\
\hline In-hospital Arrests, \% (n) & $58.6(17)$ & $78.0(39)$ & .09 \\
\hline Witnessed Arrest, \% (n) & $92.9(26)$ & $93.6(44)$ & 1.00 \\
\hline Bystander CPR, \% (n) & $85.2(23)$ & $95.6(43)$ & .18 \\
\hline Initial Rhythm, \% (n) & & & .78 \\
\hline $\begin{array}{l}\text {-Ventricular Tachycardia/ } \\
\text { Fibrillation }\end{array}$ & $43.3(13)$ & $49.0(24)$ & \\
\hline -Pulseless Electrical Activity & $46.7(14)$ & $44.9(22)$ & \\
\hline -Asystole & $10.0(3)$ & $6.1(3)$ & \\
\hline Defibrillation, \% (n) & $51.7(15)$ & $51.0(25)$ & .52 \\
\hline ROSC (minutes), median (IQR) & $5(2-20)$ & $10(3-15)$ & .93 \\
\hline TTM Administration, \% (n) & $26.7(8)$ & $40.0(20)$ & .33 \\
\hline TISS-28, median (IQR) & $28.5(26-33)$ & $27.0(23-33)$ & .41 \\
\hline $\begin{array}{l}\text { Length of ICU Stay (days), } \\
\text { median (IQR) }\end{array}$ & $9(4-18)$ & $9(6-17)$ & .51 \\
\hline $\begin{array}{l}\text { Length of Hospital Stay (days), } \\
\text { median (IQR) }\end{array}$ & $19.5(10-35)$ & $27.5(11.5-37.5)$ & .48 \\
\hline
\end{tabular}

Abbreviations: $\mathrm{SD}=$ Standard Deviation, $\mathrm{BMI}=$ Body Mass Index, $\mathrm{CCI}=$ Charlson Comorbidity Index, IQR $=$ Interquartile Range, $\mathrm{CPC}=$ Cerebral Performance Category Scale,$\quad \mathrm{CPR}=$ Cardiopulmonary Resuscitation, $\quad \mathrm{ROSC}=$ Return of Spontaneous Circulation, TTM $=$ Targeted Temperature Management, ICU $=$ Intensive Care Unit, TISS-28 $=$ Therapeutic Intervention Scoring System

\section{Results}

\section{Admission clinical characteristics}

Overall our sample is young (mean age $53 \pm 17$ years), with equal racial representation: white (43\%), black (25\%), and Hispanics (20\%). The majority had good baseline functioning, only $7 \%$ of patients having a pre-event psychiatric diagnosis, moderate grade (median 3 (IQR 1-4)) on the CCI, $71 \%$ were in-hospital arrests, $47 \%$ presented with shockable rhythms, median ROSC was 8.5 min (IQR 3-15), and 35\% were eligible for TTM with $92 \%$ cooled to $32-34^{\circ}$. Median length of ICU and hospital stay was 9 (IQR 5-18) and 22 (10-36) days, respectively.

$38 \%(n=30)$ of patients were women. No significant gender specific differences were found for age, race, CCI scores, premorbid CPC or psychiatric diagnoses, arrest related variables, rates of TTM administration, or length of intensive care unit or hospital stays (Table 1).

\section{Outcomes}

Women were found to have significantly worse RBANS scores for total, visuospatial, language, and attention domains. Women were also found to have significantly worse M-PSMS and CES-D scores (Table 2). These significant gender specific differences were maintained for RBANS, M-PSMS, and CES-D scores, in both uni- and multivariate models, after adjusting for age, initial rhythm, time to ROSC, and TTM administration (Table 3). There were no significant gender specific 
Table 2

Comparing Women and Men in Various Outcome Measures.

\begin{tabular}{|c|c|c|c|c|c|c|}
\hline Outcome Measures & $\begin{array}{l}\text { Impairment cut- } \\
\text { off (Scale Range) }\end{array}$ & $\begin{array}{l}\text { Total Sample } \\
\text { Impaired No. } \\
(\%)\end{array}$ & Total Sample Raw scores mean \pm SD & Women Raw scores mean \pm SD & Men Raw scores mean \pm SD & p-value \\
\hline RBANS, mean \pm SD & $79^{\mathrm{a}}(40-160)$ & $52(67)$ & $71.2 \pm 19.4$ & $64.9 \pm 19.3$ & $74.8 \pm 18.7$ & .01 \\
\hline -Immediate Memory & $79^{\mathrm{a}}(40-160)$ & $50(65)$ & $75.7 \pm 20.9$ & $72.6 \pm 21.9$ & $77.5 \pm 20.4$ & .19 \\
\hline -Visuospatial & $79^{\mathrm{a}}(40-160)$ & $32(42)$ & $83.9 \pm 23.8$ & $76.2 \pm 25.1$ & $88.3 \pm 22.0$ & .03 \\
\hline -Language & $79^{\mathrm{a}}(40-160)$ & $36(47)$ & $78.1 \pm 17.0$ & $73.7 \pm 15.1$ & $80.6 \pm 17.7$ & .03 \\
\hline -Attention & $79^{\mathrm{a}}(40-160)$ & $48(62)$ & $73.4 \pm 19.2$ & $64.9 \pm 17.0$ & $78.2 \pm 18.8$ & .004 \\
\hline -Delayed Memory & $79^{\mathrm{a}}(40-160)$ & $50(65)$ & $71.2 \pm 22.2$ & $65.4 \pm 22.3$ & $74.6 \pm 21.8$ & .08 \\
\hline M-PSMS, mean \pm SD & $(6-30)$ & & $11.8 \pm 4.9$ & $13.6 \pm 5.6$ & $10.6 \pm 4.2$ & .02 \\
\hline CPC, \% (n) & $3^{\mathrm{b}}(1-4)$ & $33(41)$ & & & & .40 \\
\hline -СРC 1 & & & $27.5(22)$ & $20.0(6)$ & $32.0(16)$ & \\
\hline -CPC 2 & & & $31.3(25)$ & $30.0(9)$ & $32.0(16)$ & \\
\hline- СРC 3 & & & $41.3(33)$ & $50.0(15)$ & $36.0(18)$ & \\
\hline CES-D, mean \pm SD & $16^{\mathrm{c}}(0-60)$ & $31(43)$ & $17.6 \pm 13.7$ & $22.8 \pm 15.5$ & $14.3 \pm 11.5$ & .02 \\
\hline PCL-C, mean \pm SD & $36^{\mathrm{d}}(17-85)$ & $21(30)$ & $32.6 \pm 14.2$ & $35.8 \pm 15.6$ & $30.5 \pm 12.9$ & .13 \\
\hline
\end{tabular}

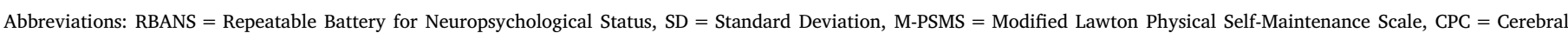
Performance Category Scale, CES-D = Center for Epidemiological Studies-Depression, PCL-C = Post-Traumatic Stress Disorder Checklist - Civilian

p-values reflect comparison of women and men for various outcome measures.

${ }^{\text {a }}$ Cut-off score for low average [19].

b Suggested CPC cut-off [7].

c Suggested CES-D cut-off [16].

${ }^{\mathrm{d}}$ Suggested PCL-C medical setting cut-off [18].

differences found in discharge CPC or PCL-C scores.

\section{Discussion}

This study aimed to explore gender differences among CA survivors and found that women had worse cognitive, functional, and psychiatric outcomes at discharge. There were no significant gender specific differences in age, initial rhythm, time to ROSC, number of therapeutic treatments or TTM administration; however, models were adjusted for these factors as they have previously been shown to be different between men and women $[1,2]$.

Women in this cohort scored significantly worse on the RBANS, indicating greater cognitive impairment than men. One potential explanation for this result is that men in this sample may have had greater cognitive reserve through different levels of education and occupational attainment prior to the CA. This higher reserve could enable men to either withstand more damage to the brain or compensate for existing damage better than women [20]. Further, in our study, the specific cognitive domains that showed the biggest gender differences were visuospatial, language, and attention. These tasks localize to the frontoparieto-temporal lobes, and are similar to gender differences reported in Alzheimer's disease [21]. Notably, imaging studies have shown larger hippocampi in women than men after adjusting for total brain size [22], suggesting higher brain reserve for memory impairment in women [20]. This may explain their immediate and delayed memory not being significantly impacted compared to men.

Overall, the prevalence of cognitive impairment in this study is greater than a recent similar inquiry [23], however a wide range $(6-100 \%)$ has been reported in a systematic review on incidence of cognitive impairment at six months [24]. While our patients received a relatively low rate of TTM, we do not consider this a contributing factor to the greater prevalence of cognitive impairment. Instead, this discrepancy may be based on the fact that our patients were admitted with many comorbidities as evidenced by the high pre-morbid CCI, and with a far greater percentage of non-shockable rhythms and prolonged ICU stays. Additionally, the metrics of the neuropsychological tools utilized plays a major role in comparing incidence across studies. It is possible that commonly used measures such as the Cog-Log, the Telephone Interview for Cognitive Status (TICS), or the Mini Mental State Examination (MMSE) may not be as sensitive and domain specfiic as the RBANS, thereby failing to fully identify certain deficits, as evidenced by a recent, prospective study that demonstrated no cognitive impairment at the 1-, 6-, and 12-month time points [25].

Women's significantly poorer outcomes in the M-PSMS is concordant with previous stroke research, where women have been shown to have worse functional independence at discharge even after

Table 3

Gender Based Associations with Cognitive, Functional, and Psychiatric Outcomes.

\begin{tabular}{|c|c|c|c|c|c|c|c|c|c|}
\hline \multirow[t]{2}{*}{ Outcome measures } & \multicolumn{3}{|l|}{ Gender } & \multicolumn{3}{|c|}{ Gender + Age } & \multicolumn{3}{|c|}{ Gender + Age + Clinical Variables ${ }^{\mathrm{a}}$} \\
\hline & OR & $95 \% \mathrm{CI}$ & p-value & OR & $95 \% \mathrm{CI}$ & p-value & OR & $95 \% \mathrm{CI}$ & p-value \\
\hline RBANS & -9.9 & $-18.8,-1.0$ & .03 & -9.9 & $-18.9,-0.8$ & .03 & -11.2 & $-20.2,-2.2$ & .02 \\
\hline -Immediate Memory & -4.9 & $-14.8,5.0$ & .33 & -5.4 & $-15.4,4.6$ & .29 & -6.5 & $-16.8,3.9$ & .22 \\
\hline -Visuospatial & -12.2 & $-23.1,-1.2$ & .03 & -12.8 & $-23.9,-1.8$ & .02 & -14.2 & $-24.6,-3.7$ & .009 \\
\hline -Language & -6.8 & $-14.8,1.1$ & .09 & -6.2 & $-14.2,1.7$ & .12 & -7.6 & $-15.9,0.6$ & .07 \\
\hline -Attention & -13.4 & $-22.0,-4.8$ & .003 & -13.1 & $-21.7,-4.4$ & .004 & -13.2 & $-22.1,-4.4$ & .004 \\
\hline -Delayed Memory & -9.1 & $-19.5,1.2$ & .08 & -9.0 & $-19.5,1.5$ & .09 & -11.7 & $-22.3,-1.0$ & .03 \\
\hline M-PSMS & 3.0 & $0.8,5.2$ & .008 & 3.1 & $0.9,5.3$ & .006 & 3.4 & $1.1,5.6$ & .005 \\
\hline $\mathrm{CPC}$ & 1.8 & $0.7,4.5$ & .22 & 2.0 & $0.8,5.2$ & .16 & 3.2 & $1.1,9.4$ & .04 \\
\hline CES-D & 8.5 & $2.2,14.9$ & .009 & 8.3 & $1.8,14.7$ & .01 & 8.7 & $1.6,15.7$ & .02 \\
\hline PCL-C & 5.3 & $-1.5,12.1$ & .13 & 4.6 & $-2.2,11.5$ & .18 & 3.8 & $-3.6,11.3$ & .31 \\
\hline
\end{tabular}

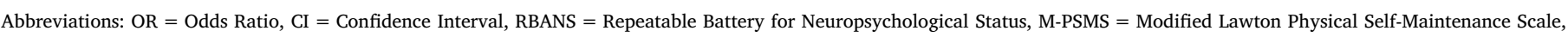
CPC = Cerebral Performance Category Scale, CES-D = Center for Epidemiological Studies-Depression, PCL-C = Post-Traumatic Stress Disorder Checklist - Civilian.

${ }^{\text {a }}$ Initial cardiac rhythm, time to return of spontaneous circulation, and Targeted Temperature Management. 
adjusting for baseline differences between genders in demographics or clinical variables [4]. Additionally, higher CES-D scores among women in our study is consistent with the findings that women have higher rates of depression than men in post stroke and general populations [5]. Taken together, these results may indicate that CA affects women in a more detrimental way than men possibly due to differences in hormones [2] or brain reserve [20].

There are a number of limitations in this study. First, there was no administration of a separate screening tool to measure elements of cognitive reserve, such as occupation, education, and leisure activities; thus, future studies should validate the hypothesis that men have greater reserve. Further, this study was a cross sectional examination of gender differences at discharge. Some of the recovery patterns may change over time, as survivors resume their lives in the real world. Thus, a prospective, longitudinal design that follows patients' recovery trajectories after CA and includes pre-morbid elements of cognitive reserve is warranted in order to confirm these preliminary findings and to justify gender-specific clinical care interventions.

\section{Conclusions}

Women have worse cognitive, functional, and psychiatric outcomes at hospital discharge after cardiac arrest than men. Further inquiry is necessary to understand the underlying mechanisms contributing to these gender differences after cardiac arrest, which, in turn, will help us to define gender-specific interventions.

\section{Conflicts of interest}

Sachin Agarwal (corresponding author), Alex Presciutti, Jayati Verma, Marykathyrn Pavol, Deepti Anbarasan, Daniel Brodie, Leroy E. Rabbani, David J. Roh, Jan Claassen: Reports no disclosures.

Soojin Park: NIH/NINDS (K01ES026833).

Yaakov Stern: NIA RO1 AG14671.

\section{Acknowledgments}

The authors are profoundly indebted to all of their patients for their participation to the project; the authors thank Ashley Rodriguez and Cristina Falo for their support in collecting data.

\section{Appendix A. Supplementary data}

Supplementary data associated with this article can be found, in the online version, at https://doi.org/10.1016/j.resuscitation.2018.01.036.

\section{References}

[1] Kim L, Looser P, Swaminathan R, Horowitz J, Friedman O, Shin JH, et al. Sex-based disparities in incidence, treatment, and outcomes of cardiac arrest in the United States, 2003-2012. J Am Heart Assoc 2016;5:e003704.

[2] Ng YY, Wah W, Liu N, Zhou SA, Ho AF, Pek PP, et al. Associations between gender and cardiac arrest outcomes in Pan-Asian out-of-hospital cardiac arrest patients.
Resuscitation 2016;102(May):116-21.

[3] Nys GM, van Zandvoort MJ, de Kort PL, van der Worp HB, Jansen BP, Algra A, et al. The prognostic value of domain-specific cognitive abilities in acute first-ever stroke. Neurology 2005;64:821-7.

[4] Gargano J, Wehner S, Reeves M. Sex differences in acute stroke care in a statewide stroke registry. Stroke 2008;39:24-9.

[5] Paradiso S, Robinson R. Gender differences in poststroke depression. J Neuropsychiatry Clin Neurosci 1998;10:41-7.

[6] Bosson N, Kaji AH, Fang A, Thomas JL, French WJ, Shavelle D, et al. Sex differences in survival from out-of-hospital cardiac arrest in the era of regionalized systems and advanced post-resuscitation care. J Am Heart Assoc 2016;5:e004131.

[7] Safar P. Resuscitation after brain ischemia. In: Safar P, Grenvik P, editors. Brain Failure and Resuscitation. New York: Churchill Livingstone; 1981. p. 155-84.

[8] Ely EW, Inouye SK, Bernard GR, Gordon S, Francis J, May L, et al. Delirium in mechanically ventilated patients: validity and reliability of the confusion assessment method for the intensive care unit (CAM-ICU). J Am Heart Assoc $2001 ; 286: 2703-10$

[9] Sessler CN, Gosnell MS, Grap MJ, Brophy GM, O’Neal PV, Keane KA, et al. The Richmond Agitation-Sedation Scale: validity and reliability in adult intensive care unit patients. Am J Respir Crit Care Med 2002;166:1338-44.

[10] Perkins GD, Jacobs IG, Nadkami VM, Berg RA, Bhanji F, Biarent D, et al. Cardiac arrest and cardiopulmonary resuscitation outcome reports: update of the Utstein resuscitation registry templates for out-of-hospital cardiac arrest: a statement for healthcare professionals from a task force of the International Liaison Committee on Resuscitation (American Heart Association, European Resuscitation Council, Australian and New Zealand Council on Resuscitation, Heart and Stroke Foundation of Canada, InterAmerican Heart Foundation, Resuscitation Council of Southern Africa, Resuscitation Council of Asia); and the American Heart Association Emergency Cardiovascular Care Committee and the Council on Cardiopulmonary, Critical Care, Perioperative and Resuscitation. Resuscitation 2015;96:328-40.

[11] Agarwal S, Presciutti A, Roth W, Matthews E, Rodriguez A, Roh DJ, et al. Determinants of long-term neurological recovery patterns relative to hospital discharge amonge cardiac arrest survivors. Crit Care Med 2018;46(February (2)):e141-50.

[12] Miranda DR, de Rijk A, Schaufeli W. Simplified Therapeutic Intervention Scoring System: the TISS-28 items: results from a multicenter study. Crit Care Med 1996;24:64-73.

[13] Schober A, Holzer M, Hochrieser H, Posch M, Schmutz R, Metnitz P. Effect of intensive care after cardiac arrest on patient outcome: a database analysis. Crit Care Med 2014;18(April (2)):R84.

[14] Randolph C, Tierney M, Mohr E, Chase T. The repeatable battery for the assessment of neuropsychological status (RBANS): preliminary clinical validity. J Clin Exp Neuropsychol 1998;20:310-9.

[15] Lawton M, Brody E. Assessment of older people: self maintaining and instrumental activities of daily living. Gerontologist 1969;9:179-86.

[16] Lewinsohn P, Seeley J, Roberts R, Allen N. Center for Epidemiological StudiesDepression Scale (CES-D) as a screening instrument for depression among community-residing older adults. Psychol Aging 1997;12:277-87.

[17] Weathers F, Huska J, Keane T. PCL-C for DSM-IV. Boston: National Center for PTSD - Behavioral Science Division; 1991.

[18] Using the PTSD checklist. National Center for PTSD [Online]. 2017 Available at: https://sph.umd.edu/sites/default/files/files/PTSDChecklistScoring.pdf (Accessed 15 August 2017)

[19] Randolph C. RBANS Update. Bloomington: PsychCorp; 2012.

[20] Stern Y. Cognitive reserve in ageing and Alzheimer's disease. Lancet Neurol 2012;11:1006-12.

[21] Laws K, Irvine K, Gale T. Sex differences in cognitive impairment in Alzheimer's disease. World J Psychiatry 2016;6:54-65.

[22] Cahill L. Why sex matters for neuroscience. Nat Rev Neurosci 2006;7:477-84

[23] Steinbusch CVM, van Heugten CM, Rasquin SMC, Verbunt JA, Moulaert VRM Cognitive impairments and subjective cognitive complaints after survival of cardiac arrest: a prospective longitudinal cohort study. Resuscitation 2017:120:132-7.

[24] Moulaert VR, Verbunt JA, van Heugten CM, Wade DT. Cognitive impairments in survivors of out-of-hospital cardiac arrest: a systematic review. Resuscitation 2009;80(March (3)):297-305.

[25] Raina KD, Rittenberger JC, Holm MB, Callaway CW. Functional outcomes: one year after cardiac arrest. BioMed Res Int 2015;2015(8):1-8, 